\title{
Visual Arts Marketing: The Brand Equity Challenge Facing Galleries
}

Nicole Stegemann, (E-mail: n.stegemann@uws.edu.au), University of Western Sydney, Australia Beverley Thompson, (E-mail: b.thompson@uws.edu.au), University of Western Sydney, Australia

\begin{abstract}
This article addresses the challenges facing art galleries in the Sydney metropolitan area with regards to maximising their brand equity. It takes a case study approach, and investigates art galleries' sources of brand equity and the implications for their marketing communications strategies. The research has shown that art galleries have a good understanding of their brand equity entities, however, have to learn to coordinate them successfully. Further, the different types of galleries examined employ and believe in a different mix of marketing communications efforts reflecting their objectives and resources. However, their strategies are not always customer orientated, and lack supporting research. This article is part of a larger research project investigating brand equity in the arts in Australia.
\end{abstract}

\section{INTRODUCTION}

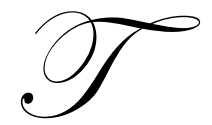

his article will explore the concept of brand equity in the marketing of the visual arts. Art galleries form an integral component of this system, Theoretical issues relating to brand equity, to the visual arts as a "marketable product ", and to the role of arts marketing will be discussed in the process of linking creative works with consumers willing to exchange monetary resources for creative purchases. The article will present the 'Model of Brand Equity in the Visual Arts' developed by the authors, which goes some way towards explaining why several sources of brand equity must be considered in the marketing of visual arts products. The article will conclude with a qualitative examination of the arts marketing, and brand-equity development practices of three interesting visual arts galleries in Sydney, Australia. While an examination of just three galleries doesn't hope to provide a full-exposition of the entire array of visual arts outlets, it does provide a sample of some of the particular marketing issues that are unique to visual arts galleries.

\section{BACKGROUND}

\section{Brand Equity Concept}

Consumers use brands as signals to determine the nature of products including their service quality and reliability as well as image and status (Swait et al. 1993). A brand includes elements such as a name, logo, slogan and combinations of these elements. The rationale of consumer-perceived brand equity is that a brand facilitates the processing and retrieval of information (Hoyer and Brown 1990), and hence, provides the benefit of easier product differentiation and consumer recognition. Companies enhance brand equity through the design of sound marketing communications strategies using different types of media such as public relations, personal selling, and advertising tailored to target market specifications. 
The literature on consumer perceived brand equity concepts produces various definitions usually using descriptions based on images and consumer associations. The widely used brand equity concept by Keller (2003) describes brand equity using the two main source elements brand awareness (recall \& recognition) and brand image (favourability, uniqueness and strengths of brand associations, attributes, benefits and attitudes) of a brand. The branding outcomes ultimately incorporate consumer behaviour constructs such as brand loyalty, referral, and premium price.

\section{Arts and Culture}

The concept of culture has its roots in anthropology and the behavioural sciences. An early definition was provided by (Tyler 1981), who described culture as a complex sum total including knowledge, belief, art, morals, law, customs and any other traits that are acquired by humans as part of society. (Wadia 1965) defined culture as "..the integrated sum total of learned behavioural traits that are manifest and shared by members of a society"... .. "plus the manifestation of these behavioural traits, such as institutions and artefacts..". "The arts", as part of aesthetic culture includes elements such as music, literature, poetry, dance, drama, and visual art, film-making, story-telling, festivals, journalism, publishing, television, radio, and various aspects of design.

In fact, a cultural product is an intrinsic manifestation of a creative product in that it must be different from other creative products, and therefore, it is not mass produced. Visual arts products commence with a creative idea, which can be articulated through various types of art such as a painting, sculpture or photograph. Visual artwork is usually made accessible to the general public through art galleries, exhibitions and auctions. Principles of massproduction, mass-retailing and mass-marketing are at variance with the principles espoused by marketers of arts objects, which rely on their offerings being positioned as unique, creative, informative, reflective, beautiful or controversial - but not mass-produced or mass-marketed.

Galleries exist to provide retail exchange outlets whereby the works of practising artists are displayed to aspiring consumers of creative works. Arts galleries are organisations involved as agents between the visual artist or creator, and the purchaser. As such, galleries act as arts marketers, and so must understand and follow many of the same principles as retailers of non-artistic products. They have to maintain equilibrium between satisfying customer needs and achieving creative missions (Rentschler 1999). With an increasing number of arts organisations and a growing competition for the consumer dollar, arts organisations in Australia have been forced to adopt a more marketing-oriented focus. Most art galleries have developed specific marketing strategies, especially brand positioning strategies, and well-formulated marketing communications strategies in order to survive in the market place. As such, gallery operators/managers need to have an understanding of brand management and the underlying concept of brand equity. This is the focus of this paper.

In "the arts" most brand elements are of a somewhat transient nature, which can be largely explained through the likely change of the key brand and product elements of an arts organisation. They change either in an evolving manner, or even quite radically, as artists and their work change and evolve.

Visual arts products consist of several independent entities, each with their individual brands and levels of brand equity. For the visual arts, the brand equity entities usually consist of - the gallery, the gallery proprietor, the artist, the type of customers, the art genre (portraits, landscapes, sculptures, abstract works, etc.), the government, and perhaps an agent and a sponsor. Even the concept of a "customer" is not clear-cut in the visual arts. Customers or patrons, may range from private individuals, collectors or traders, corporate purchasers, or Government or private art museums. The visual arts transaction may take place via an art-auction, or a private sale. The arts object may be a newly-created piece for which the purchaser takes possession from its creator, or it may be an artefact that has had a long history and a succession of owners. Art galleries have the responsibility to work with and represent these diverse sets of brand equity entities, each of which comes with its own brand and brand equity. The mission as a gallery is to build the overall brand equity of the gallery, by summating the brand equity components of each of the contributing entities. The marketing communications task for the gallery thus must be a combination of awareness-building and image-building of the gallery as an entity, and also for its constituent entities, especially that of the featured artist. 
The various sources of brand equity in the visual arts, the interactions between contributing entities, and the coordination role of the gallery at the nexus are demonstrated in Figure 1.

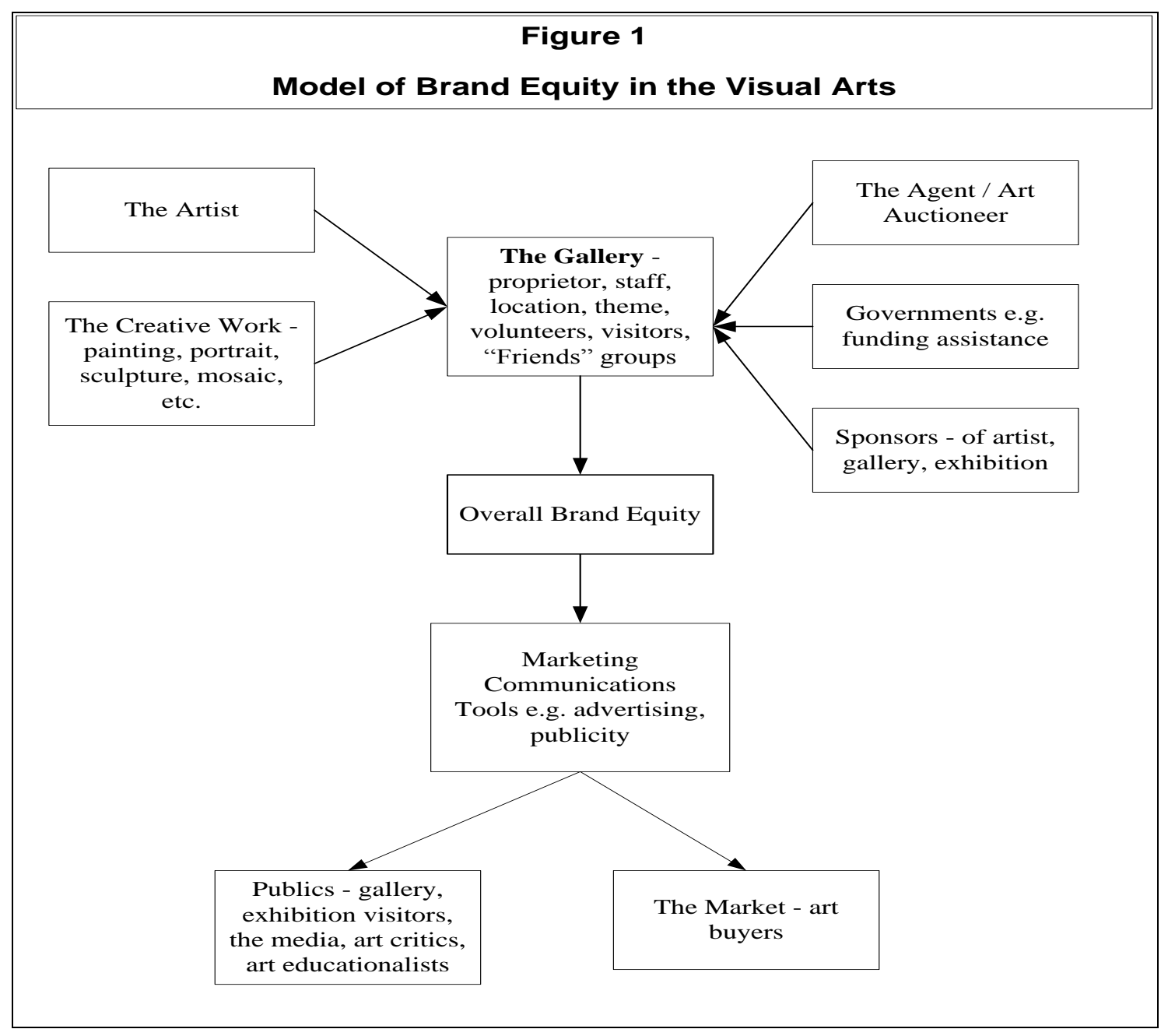

Figure 1 illustrates the brand equity path that encompasses the artist, and his or her creative work, and the gallery which collectively form a "brand identity" as a combined visual arts entity. This paper largely examines the brand equity role and contribution of the visual art gallery. Subsequent arguments will point out that many galleries operate in somewhat of a brand equity vacuum, ignoring the benefits to be had by capitalising on a summation of the brand equity contributions possible from the multitude of sources in the system represented in Figure 1.

The following specific research questions are addressed in this article:

1. What constitutes "brand equity" in the offerings of visual arts galleries?

2. What role does the brand equity of contributing sources play, in determining the overall brand equity of art galleries?

3. How effectively do art galleries use marketing communications to assist in the development of, and enhancement of brand equity? 
This article will examine the above research questions, both theoretically, and by referral to case studies of three Sydney galleries.

\section{RESEARCH METHODOLOGY}

In light of the research questions an exploratory approach was identified as the best approach for this study, Research data from various sources was utilised, in which in-depth interviews with art gallery managers represented the prime source. Additionally, data was gathered through other sources such as extensive Internet and database searches of the various arts organisations and relevant government bodies. This research strategy utilises a case study approach, as "..it attempts to examine a contemporary phenomenon in its real life context" (Yin, 1981).

This qualitative study is part of a greater research project in which performing and visual arts organisations have been interviewed with respect to their development of brand equity strategies. This article focuses on three visual arts organisations, namely art galleries, in Sydney, Australia, which represent a diverse set of organisational entities. They include a well-established gallery representing later-career artists, a gallery supporting younger/emerging artists and a non-profit gallery. In-depth interviews were conducted with the managers of the art galleries using a carefully developed interview-guide to ensure consistency in the interview process. After completion of the interviews, transcripts were produced which allowed for a detailed analysis of the inherent themes and issues which will be examined in the context of the model depicted in Figure 1.

\section{CASE STUDIES}

\section{Case Study 1 - Well-established Gallery}

David is the director of a well-known reputable art gallery that was established in 1991. The gallery has two very stylish and contemporary showrooms, which are located close to each other in historical buildings, one of them with a reputation of having been the bohemian hang-out in the 60's and 70's. The gallery is based in an affluent trendy suburb in Sydney with a high percentage of young singles in close proximity to a large gay community. The gallery has two full time staff including the director, and four casual staff working on a part-time basis. According to David, the gallery's overall objective is to be:

“..not so much a cutting-edge gallery... ..we sort of want to be known as one of the premier contemporary galleries here in Sydney,.. ..we have mid to late career artists who have already established a name for themselves."

The gallery only represents 13 well-known artists retailing their artwork between AUD 10,000 and AUD 90,000. About 12 solo exhibitions are hosted per year turning over approximately AUD1.2 million in 2003-2004. The artists are seen as the most important brand entities, as their reputation and art work shapes the gallery. In addition to the main business, the gallery offers a full service in contemporary art including evaluations of fine arts collections.

It is quite common for well-established galleries to carry their owner's name. As such it is often perceived as being the most important source of brand entity for a gallery. This is the case with this gallery. The owner's name is used to promote the gallery since he enjoys prestige and standing in the art world, with formal qualifications and wide experience in curatorial matters. He is a commercial and private dealer, approved valuer, auctioneer and advisor to private, corporate and public collectors who respect his credentials. Customers appreciate his knowledge of, and eye for art in Australasia; he especially knows and lives contemporary, tribal and indigenous art from the South Pacific. The sleek modern showroom conveys an appropriate "feel" for contemporary art while conserving the history of the building. Business cards feature the slogan "Twentieth Century Contemporary Australian and International Works of Art" but this does not seem to be further promoted. 
The main form of competition is seen in other art galleries' artists and their work. There is also strong competition for the consumer dollar and time, from many choices of alternative activities such as surfing, and other purchases such as holidays, furniture and home-improvements.

The gallery is clearly focused on its image, as a serious and sophisticated gallery, in order to ultimately maximise its profit. To achieve these objectives, a niche marketing strategy is applied in which the target segments include business customers such as interior designers, and the gay and lesbian community living in the Eastern and North Shore suburbs of Sydney. Wooing this cohort therefore requires reasonably specialist marketing communications strategies. For example, the entertainment and social value of opening shows is not perceived as offering a competitive advantage. Nor is it felt that customers patronise the art gallery because of a lack of knowledge about, and awareness of, art. Instead the gallery's role is to facilitate the exposition of recent and sophisticated visual arts artefacts, to a knowledgeable and sophisticated clientele. As such David emphasises the importance of his gallery's communications strategy of "..raising their profile through art publications and on the net.."

David believes that the gallery has established a strong, favourable and unique brand image, which has been built through its marketing communications efforts over the past 14 years. The positioning strategy is reflected in the gallery's marketing communications efforts, as described by David:

"We don't pretend to be cutting-edge, but our positioning strategy is to be the leading contemporary gallery here in Sydney, so with that we align ourselves with a communication message through the best contemporary magazines, the best contemporary publications, the best contemporary shows - that type of thing."

People living in the Eastern suburbs of Sydney are positively aware of the gallery due to its long-term existence. Further, the gallery is certainly promoting itself through the chosen location, as the nowadays affluent area is unique with respect to its bohemian history, the mixture of modern and classical architecture, and the vibrancy of the area created by cafés, bars and restaurants. The prominent street signage and the big lit-up windows of the showrooms are part of this ambience. Further, David markets the gallery through different media such as high-profile art publications, in which the owner is always highly profiled in order to reinforce the brand personality of the gallery. The advertisements usually reflect the theme and purpose of the art exhibition, a profile of the artist, and details of the works in the exhibition. In order to ensure adequate press releases of the opening shows, a public relations person is used and journalists as well as arts writers are invited. Art fairs act as another forum, and the gallery is represented at art fairs such as the annual 'Melbourne Art Fair' where it represents the largest contributor. Additionally, exhibition spaces are rented in Melbourne and Adelaide a few times a year, when the gallery goes on tour, to drive the brand to other specific locations.

People are drawn to the gallery's website to see for themselves the variety of art work being exhibited, the gallery's calendar, information conveyed via press releases, and information about the artists and the objects d'art. The mailing list is a critical asset and is viewed as important to any successful gallery. The list includes a high percentage of loyal business customers as well as collectors, who usually buy at least on piece of art work from every show. A huge effort is put into keeping the database up-to-date, which is a particular challenge in this area of Sydney where residents tend to move house every 6 to 12 months. Relationship marketing is important to this gallery. The owner-manager builds firm relationships with his customers. This is reiterated via regular telephone calls, mail-outs and emails.

Other aspects of the gallery's marketing communications strategy were investigated. David explained that there is no set marketing communications budget in any one period. The gallery covers all costs of cataloguing, photography, etc. Exhibiting artists contribute 50\% to their advertising expenses, and therefore, the artists are often guiding the level of advertising efforts. Sponsorship marketing is avoided as it is seen as being a distraction to the art work and artists. 


\section{Case Study 2 - Emerging Artists}

A small commercially-run art gallery, which is located in a trendy affluent suburb in Sydney, was established in 1997 by its director, Andrew. This suburb is characterised by affluent couples and families that enjoy a village atmosphere in the heart of Sydney. The art gallery employs 2 full-time staff and specialises in contemporary art created by young emerging talented artists. Each year, about 20 exhibitions are organised, which attract around 200 to 400 visitors per opening show. The gallery has an annual turnover of about AUD 200,000. Andrew's aim is it to act as a resource for people interested in emerging art work, and has established a gallery that provides for younger artists. Galleries featuring well-established artists usually exhibit more expensive works, and may only represent about 20 to 30 artists, while this gallery represents about 200 artists. This type of artists is often not represented by other galleries. This gallery provides emerging artists with a wonderful opportunity to have their works exposed.

The target markets range from artistic professionals and arts-industry related people, friends \& family of the artists, and people generally interested in the arts. Distinct marketing communications and customer relationship strategies are applied to reach these three segments.

The strategy of providing lots of different artists promoting the name of the gallery (and not the owner's name) is seen as the key to its success. To build awareness for the gallery a global name was chosen to emphasis the nature of the gallery and not the gallery owner. David explains:

“Oh, brand name's very important, I think. ..we came up with a name.. ..because it does imply quite a big range. I don't believe in utilising an owner's name as the brand name... ..there's a lot of ego in the industry and therefore a lot of galleries are marketed under the name of the actual gallery owner.. .. 95\% of galleries are like that. This means that at the end of the day, the brand is built around that one person. I don't think that's really a sustainable thing long-term, because it means that that business only has legs for as long as that owner or director is around. I think loyalty to that brand could drop off quite quickly if that person wasn't around. So we built....in the same way you might any other product or business - a brand suggesting the actual product of the business rather than the person who is running it."

Andrew sees his main competition for gallery patronage as being other arts organisations and exhibitions, other forms of entertainment, outdoor/sporting activities and home-based activities. He perceives that competition is not so much for the consumer dollar, but rather for time. People are working longer hours and/or have family commitments, which results in people turning up late for the opening shows or not coming at all. Hence, Andrew has been organising events including 'Meet the Artist' on Saturdays to accommodate the needs of working people, and families with small children. Andrew believes that a key to achieving a competitive advantage is to counter-balance the lack of knowledge and awareness of the gallery and the arts in general. He suggests that it is not so much that people are not interested in the arts, but rather that they are not fully informed about the different activities on offer pertaining to the various art forms. Participating galleries must therefore take an active role in communicating their existence, programs and schedules to a prospective target market.

The gallery's geographical position contributes to the gallery's popularity, as it is easy to reach, situated in a well-frequented area, the domain of a young outgoing crowd that is interested in fashion, artwork, and any contemporary and designer products.

A relationship has been built between the brand and the consumer through the gallery's positioning strategy that promotes young unknown and emerging artists. Its main positioning objective is to be seen as the gallery that finds the "future superstars". Further, the diversity and quality of the art work plays an important key role, and customers should have the perception that they may buy affordable artwork that represents a potential worthy investment. The gallery is well-known in the Eastern suburbs of Sydney, as Andrew states: 
"I think the people who come to know us, whether it's through an exhibition or through an invitation, would be quite familiar with the brand, particularly once they've been here. I think because of our specific brand as a gallery, we are seen as being more than just another Paddington gallery."

Andrew tends to approach the professional customers such as interior designers and architects through telephone calls. His intention is to establish an initial contact, and to inform them about their products and consulting services and upcoming events.

The gallery is known for its large number of exhibitions and the variety of artists and art work, whether paintings, sculptures, etchings etc. It is seen as a social place to meet like-minded people, and talk about art work amongst other things. The exhibitions themselves play a vital role in building the gallery's brand image, and the brand awareness level of the gallery is expected to increase long-term because of the large number and the variety of exhibitions. Each exhibition usually has a title such as the "Love Show" and "Valentine's Show", which is complemented by suitable music, poetry readings, etc. plus drinks and finger food to attract the different types of artinterested people.

This variety and artist-opportunity make up the main components of the gallery's brand equity, and generates people's interest in the gallery. This is expressed in the high referral rate, and increases in audience numbers with every exhibition, which adds new customers and art-interested people to the mailing list. The current mailing list includes about 5000 art-interested people, who are informed of selected upcoming exhibitions via email and postal mail. The website provides general information regarding the art gallery, upcoming events, and extensively features the artists, detailing their biographies and details of their current and previous art work. The website and leaflets also provide customers with forthcoming exhibition information including the type of art, information about the artists, opening show information, and the duration of each exhibition.

David believes that the public relations part has been neglected in the past, as it is very work-intensive. However, he perceives that the gallery should work more on this side of marketing communications in the future. The marketing budget has been about AUD 1000 per exhibition, which is seen as being the bare minimum.

\section{Case Study 3 - Non-Profit Organisation}

The non-profit organisation, run by Ming Lee and George her husband, established in 1997, is situated in the heart of the city, close to Universities and Chinatown. The art organisation comprises an art gallery and an attached art consulting company. The artwork consists of ideas expressed by various arts media such as paintings, photos or sculptures. Thousands of people walk past the gallery every day because of its proximity to the business and student district. The personnel include three full-time staff plus there are a number of people sourced from universities and private intern-placement organisations, who make up the equivalent of three full-time interns.

The gallery is funded by various sources such as Federal, state, and local funding. Further resources are received through member fees, rare artwork sales, and, financial and non-financial donations. This non-profit art gallery heavily relies on grants, which are often linked to specific projects conducted by the gallery. Additional income is generated through consulting, which will increasingly support the gallery in future, as government funding levels decrease. The operating turnover of the organisation is about AUD 250,000 a year.

According to George:

"The fundamental mission is to use contemporary art to promote a cross-cultural dialogue, and, through that, to support and develop Asian sensibilities in contemporary art. Additional goals are to support and develop young Asian-Australian artists, and to communicate new artistic influences from Asia to the general public in Sydney and Australia" 
The art gallery has a clear educational focus, and encourages the discussion, exchange and dialogue of ideas. As the gallery's focus has changed over time, the brand image had to be repositioned. The present objective is to increase brand awareness.

The demographic of the gallery's target market is young (between 20 and 45), sexy/trendy and Asianinterested. The gallery doesn't sell art work except for the unusual transaction, and at their annual fundraiser. It has little contact with art collectors per se, but more with people who wish to be involved with art, and with art dialogue. Specific ethnic groups are targeted for exhibitions with a specific ethnic theme, for instance, if the artist is Chinese, the Chinese television networks are invited to air about the exhibition. The target market is not essentially Asian, but to a certain extent people who have a taste for contemporary Asian-Australian art work. The opening shows fascinate about 200 to 300 people, peaking with 800 people for a large project.

The art work tends to be more experimental, as the gallery especially supports young artists. As the aim is to encourage dialogue between people, the art work constantly changes, and, is critical and provocative at times. The price does not play a role, as usually the work is only for sale upon request or in their annual fundraising exhibition. George does not consider the location as critical, as it is more about the idea of bringing people together, although, the central location is a plus of course. Further, as part of their consulting services, exhibitions for galleries in other states and countries are organised.

This gallery is mainly competing with other art galleries for grant money, as there is a very limited amount of funding available. George explains the notion of competition as follows:

"It's a different kind of competition, simply because we're all trying to get a certain slice of a limited pot of money, so it's not a head-to-head competition between us and ........s. It's different to that. We are in competition with the ideas of other places, because we are actually trying to promote ourselves as being a much more vital set of ideas, so we are deliberately trying to position ourselves as being more interesting than the Art Gallery of NSW, or more interesting than....... So, whether or not we achieve that, we do actually have an aim to do that."

Most galleries compete with other forms of entertainment, though, not this gallery, as it benefits from the spill-over effect of the area situated right in the middle of the Mecca of entertainment such as theatres, cinemas, etc. near Chinatown in Sydney. To engage and interest the theatre crowd and others coming past the gallery when going out for some entertainment, there is always something to get their attention, like a three meter high skeleton of a mosquito. Once, people have entered the gallery, they are usually encouraged through art work, staff members and signs to also go upstairs, and see the other parts of the show. Once enticed into the gallery, patrons seem to become loyal, many even spending their lunch breaks with colleagues at the gallery. The gallery takes on a particular role in educating people about art. Inside the gallery, artists engage people in arts-related dialogue, and explain their work. The gallery also provides information material to schools and invites school students to their free classes, and to their shows.

George suggests that the public's perception of art being boring and stuffy with viewing requiring payment, is the main problem to overcome. There is also a general lack of knowledge and appreciation for art by Australians, as well as a lack of awareness of the gallery.

With respect to the branding focus, George explains that it is not the artist but the art work that is the integral part forming the brand:

"What we're branding.. .. because, if you call the idea as a product, the authors of those ideas constantly change here, so what we are branding here is a contemporary idea's experience, I suppose."

Further the name of the art gallery has established its place amongst the arts-interested fraternity, and simultaneously serves as a logo, which people recognise. The unofficial slogan of "young, sexy and Asian" is used 
when talking to people such as journalists. However, it is not used officially in communications, such as in press releases written by the gallery, or printed on business cards.

The substantial e-mailing list contains about 2,300 contacts in the Australasian market. It is the main promotion tool to make people aware of the different shows and exhibitions. Through word of mouth, the gallery has become known to be a friendly and approachable place. Another important avenue for promotion of the gallery is through public relations, as funding becomes increasingly limited. Hence, effort is put into preparing press releases and press packages to make sure that there is a good representation of the press for each show. Artists assist by giving press conferences. Ethnic television channels regularly attend, and transmit opening shows to interested people. Last year, gallery activities were publicised in over 200 press releases. Funding is limited, being sourced mostly from private donations and government grants. It is therefore not possible to dedicate funds to a communications budget.

The gallery business also includes a consulting company which utilises Ming Lee's extensive knowledge and experiences in Asian-Australian art work. Other art galleries use the services of this consultancy to organise art exhibitions with an Asian focus, when they lack the requisite skills and knowledge. Future plans include first class art tours for collectors to places in China.

\section{FINDINGS}

This research shows that the objectives of the three types of art galleries clearly differ from each other, which is reflected in the operation of the galleries, as well as their perceptions of their principal raison d'etre, their use of marketing communications and the way they develop their respective brand reputations and the resultant brand equity.

With respect to competition, the well-established art gallery feels that it competes for the consumer dollar and time, with the art work of other art galleries, other forms of entertainment, and home-based activities. The art gallery grooming new talents also believes that it somewhat competes with other art galleries and other forms of entertainment, but feels that consumers' changed lifestyles represent another major challenge. The non-profit organisation perceives the type of art work as being critical, and recognises the challenge of having to overcome people's traditional perceptions of art galleries being boring and stuffy.

The well-established gallery still believes in building its brand equity around the owner's name, and the aura that comes with it. Its most important brand equity source is seen in their rarely changing group of high profile artists, and they believe this forms the basis of the development of strong, unique and favourable brand associations. The gallery representing the young emerging artists focussed on building its brand equity around a gallery name, which is given meaning through the choice of artists, art work, and the arrangement of events such as opening shows. The nonprofit organisation also sees its advantages in choosing a brand name that becomes a valuable asset. Added to this is the additional level of brand meaning and value attained through connections with its renowned directors.

All three gallery managers agreed that lack of knowledge about their creative and business organisations, and related lack of brand awareness are the major challenges to be overcome. They each acknowledged a lack of expertise in brand equity evaluation, and that they rely predominantly on subjective estimates According to their financial resources, and types of artists and art work, various forms of marketing communications activities are employed. The positioning strategies of each of the three different types of art galleries are well-reflected in their specific target marketing descriptions, which are used to develop the most suitable marketing communications strategies.

The well-known gallery sees its customer database as its main asset and most important marketing communications tool. Its other assets and efforts include the composition of its showroom displays, location, representation in high-profile art publications, suitable and sufficient presence in press releases, and its relationships with other well-known art galleries. This gallery's strategies ensure that close long-term relationships especially with business customers are being developed, and that the community is aware of the creative merit of its collection, so patronise and support this gallery. The art gallery representing young, talented artists finds itself under greater pressure to build relationships with customers, and put a lot of effort into making initial contacts. As its budget is 
limited, it relies heavily on referrals, and a growing database for their mailing list. Contrary to the well-establish galleries, this gallery sees opportunities to cater for people's lifestyles and social needs, as well as making its opening shows an entertaining event and social encounter. This gallery has limited resources available to put sufficient time and effort into public relations, or sponsorship arrangements, both of which are seen as being potentially beneficial. The non-profit gallery also relies substantially on word of mouth, and its electronic mailing list database, as its financial resources don't allow for any form of paid marketing communications efforts. Most of the organisation's energy is put into maintaining and building relationships with the media and sponsors. Management actively attempts to establish sponsorships with companies they feel to have a common target market and similar brand values. Managers also believe in making their showrooms interesting and in utilising "door-openers" to attract people's attention and to increase awareness. The brand image of such galleries is built on the art work, and the atmosphere of the showroom that serves as a social meeting point for dialogue. Public relations largely contributes to raising brand awareness and thus contributing to the brand equity of this type of gallery.

\section{CONCLUSIONS}

The case study analysis portrayed three individual and quite different visual arts galleries in Sydney, Australia. Although unique and interesting in their own right, they each also represent a kind of prototype of gallery, and are thus interesting for their potentially broader extrapolations and the broader understanding of brand equity amongst visual arts galleries, facilitated by this qualitative analysis. The case studies clearly show that while art galleries have a good appreciation of the importance of the brand equity of their specific gallery, their long-term viability would benefit from an appreciation of the synergy inherent in interlinkages of the brand equity in each of the contributing entities (Refer Figure 1). At present, the brand equity of each contributing entity is not being fully capitalised upon. In addition, brand equity strategies are often not customer-orientated and marketing communications decisions are made intuitively. The research findings show that all three types of galleries see customers' perceptions of artists and the quality of work displayed as the crucial brand equity elements. However they each perceive the value of other marketing communications and branding elements, differently. One example pertains to sponsorship - the non-profit gallery actively embraces sponsors, the gallery promoting emerging artists appreciates the benefits of sponsorship marketing but has difficulty in attaining a balanced relationship, while the well-known gallery rejects the concept of sponsorship marketing as a distraction from the main focus of the art work.

All three types of galleries employ and believe in a different mix of marketing communications efforts which reflect both their objectives and resources. Interestingly, the well-established gallery hasn't adopted a marketing orientation nor has it developed its marketing communications around its customers to enhance brand awareness and brand image. Such galleries generally enjoy longevity of operations, and solid reputations, so they don't feel the need to be more proactive, and instead are satisfied to rest on their laurels. However, galleries searching for emerging talents see their opportunities in the market, and have been increasing their competitive advantage by being more customer-orientated. However, due to their limited financial resources, it is a slow process to enter the market and establish brand equity. The non-profit organisations are most restricted with respect to funding, and use all forms of marketing communications that are free of charge. Their focus is becoming increasingly marketing-orientated, with the increased likelihood of reduced government funding, despite their contribution as a valuable public good. None of the art galleries interviewed have mechanism in place to evaluate their marketing communication strategies, and provide a cost-benefit analysis. Therefore, the effectiveness of their strategies is unknown by them.

\section{RECOMMENDATIONS}

As the arts industry is increasingly becoming more competitive, it is essential for art galleries to fully understand how the different brand equity entities contribute to their overall brand equity. As there is a somewhat limited understanding as how to manage the different entities and measure their contribution to overall brand equity, it is recommended to improve coordination of the brand equity constituents and put measurement procedures in place. The marketing communications strategies should be based on planned outcome objectives, and not on intuition, or personal preferences. A major area of improvement in brand equity management, would be seen in the adoption of the marketing concept, and the employment of customer orientated strategies. 


\section{Further Research}

This research only focused on the arts industry from an art gallery's point of view and did not address any perspectives from the other parties involved such as the artists. Further, the customer's point of view has to be taken into consideration, which is vital to assess the marketing communications efforts of art galleries. This research is part of a greater research project, which will address the aspects mentioned above in future.

\section{References}

1. Hoyer, W. D. and Brown, S. P. (1990), Effects of Brand Awareness on Choice for a common repeat-purchase product, Journal of Consumer Research, 17(2), 141-148.

2. Keller, K. L. (2003), Brand synthesis: The multidimensionality of brand knowledge, Journal of Consumer Research, 29(4), 595-600.

3. Rentschler, R. (2002), The Entrepreneurial Arts Leader: Cultural Policy, Change and Reinvention. (1 ed.), St. Lucia: University of Queensland Press.

4. Swait, J., Erdem, T., Louviere, J., Dubelaar, C. (1983), IThe equalization price: A measure of consumerperceived brand equity, International Journal of Research in Marketing, Amsterdam, Mar, 10(1), 23.

5. Tyler, E. B. (1981) Primitive Culture: Researches into the Development of Mythology, Philosophy, Religion, Language, Art and Custom, John Murray, London.

6. Wadia, M. (1965), The Concept of Culture, Journal of Retailing, 41, 21-31.

7. Yin, R. K. (1981 ), The Case Study Crisis: Some Answers, Administrative Science Quarterly, 26(1), 58-64. 
NOTES 